\title{
Impact of thrombus aspiration in frail STEMI patients
}

\author{
Pasquale Mone ${ }^{1,2}$. Jessica Gambardella ${ }^{3,4} \cdot$ Antonella Pansini $^{2} \cdot$ Mario Rizzo $^{3}$ - Ciro Mauro ${ }^{5}$ Fabio Minicucci ${ }^{5}$. \\ Gaetano Santulli ${ }^{3,4}$ iD
}

Received: 15 February 2021 / Accepted: 24 March 2021 / Published online: 4 April 2021

(c) The Author(s) 2021

\begin{abstract}
Background Despite primary percutaneous coronary intervention (PPCI) is generally considered the best therapy in older frail adults with ST-segment elevation myocardial infarction (STEMI), the incidence of re-hospitalization for cardiovascular diseases remains significant in these patients.

Aims We hypothesized that thrombus aspiration (TA) before PPCI could be a useful treatment for reducing mortality and rehospitalizations in frail patients undergoing PPCI for STEMI.

Methods We conducted a study comparing PPCI alone $v s$ TA + PPCI in frail STEMI patients. We examined a cohort of consecutive frail patients aged $\geq 65$ years with first STEMI treated with PPCI between February 2008 and July 2015 at the Department of Cardiology of the "Cardarelli" Hospital in Naples, Italy.

Results The study was completed by 389 patients (PPCI: 195, TA + PPCI: 194). At 1-month follow-up, the rate of death from any cause was $7.0 \%$ in patients treated with PPCI alone vs $3.0 \%$ in patients treated with TA + PPCI $(p 0.036)$, whereas death from cardiovascular causes was $6.0 \%$ in the PPCI group $v s 3.0 \%$ in the TA+ PPCI group ( $p 0.028)$. Equally important, the rate of re-hospitalization due to heart failure was $7.5 \%$ in the PPCI group vs $4.0 \%$ in TA + PPCI group ( $p$ 0.025) and the rate of re-hospitalization due to acute coronary syndrome was $10.0 \%$ in the PPCI group vs $4.5 \%$ in the TA + PPCI group ( $p 0.016)$. Conclusion These results indicate the importance of TA in the treatment of STEMI in a group of high-risk patients such as elderly with frailty.
\end{abstract}

Keywords Frailty $\cdot$ STEMI $\cdot$ Thrombus aspiration

\section{Background}

Frailty has been shown to increase the risk of cardiovascular diseases [1-6]. The CONCORDANCE registry database has reported the prevalence of frailty in older adults presenting with acute coronary syndrome (ACS) showing that at least

Pasquale Mone

pasquale.mone@unicampania.it

Gaetano Santulli

gsantulli001@gmail.com; gaetano.santulli@einsteinmed.org

1 University of Campania "Vanvitelli", Piazza Miraglia, Naples, Italy

2 ASL Avellino, Avellino, Italy

3 University of Naples "Federico II", Naples, Italy

4 Einstein College of Medicine, Montefiore University Hospital, 1300 Morris Park Avenue, New York, NY 10461, USA

5 Cardarelli Hospital, Naples, Italy one-third of older adults in this setting are frail, exhibiting increased morbidity, mortality, length of critical care unit stays, and readmission rates [7]. Although primary percutaneous coronary intervention (PPCI) is the best therapy in older adults with ST-segment elevation myocardial infarction (STEMI), the incidence of restenosis, heart failure (HF), re-hospitalization for ACS and death in STEMI patients remains significant and challenging $[8,9]$.

Thrombus aspiration (TA) before PPCI has been proposed as a useful treatment to reduce oxidative stress and distal embolization, thereby improving microvascular perfusion and reducing no-reflow phenomena [10-18]. However, randomized controlled trials (RCTs) and large trial registry studies have evidenced that TA does not significantly improve clinical outcomes in STEMI subjects [19-21]. Furthermore, some studies suggest that there is no clinical benefit in using adjunctive TA in the treatment of STEMI patients undergoing PPCI, at least in the general population [19, 20, 22]. Instead, data from the Swedish Coronary Angiography and 
Angioplasty Registry (SCAAR) demonstrated that TA was associated with a significantly decreased risk of stent thrombosis [23]; the SCAAR study is considered the largest cohort of consecutive STEMI patients in whom TA has been evaluated $(42,829$ patients: more than those in all other RCTs combined).

Nonetheless, to our knowledge there are no studies investigating the effects of TA in addition to PPCI in frail patients with STEMI.

Of note, advanced age is an important determinant of severe clinical outcomes in patients with STEMI and frailty is a strong predictor of cardiovascular events [24, 25]. Thus, we hypothesized that TA before PPCI could reduce mortality and rehospitalizations in frail patients with STEMI. To test this hypothesis, we designed a study to evaluate STEMI patients with frailty, comparing results between TA and nonTA patients, with a 30-day follow-up.

\section{Methods}

This is an observational study investigating the relationship between TA use and outcome in addition to PPCI in frail STEMI patients. We examined consecutive patients with first STEMI treated with PPCI between February 2008 and July 2015 at the Department of Cardiology and PCI center of the "Cardarelli" Hospital in Naples, Italy. All patients with onset of symptoms $<12 \mathrm{~h}$ and at least 1-mm ST-segment elevation in 2 or more contiguous limb leads or at least $2 \mathrm{~mm}$ in two or more contiguous precordial leads or left bundle branch block underwent PPCI. Coronary angiography was performed as we previously described and validated [14, 26-28]. The culprit lesion was identified and crossed with an angioplasty guidewire. TA was performed by the operator, considering established angiographic selection criteria [29-32], followed by conventional PPCI to the culprit vessel. The thrombus grade was classified on the basis of previous studies [33, 34]:

- Grade 0 (G0), no angiographic characteristics of thrombus;

- Grade 1 (G1), possible thrombus presence;

- Grade 2 (G2), definite thrombus with largest dimension $\leq 1 / 2$ the vessel diameter;

- Grade 3 (G3), definite thrombus, with largest linear dimension $>1 / 2$ but $<$ twice vessel diameter;

- Grade 4 (G4), definite thrombus, with the largest dimension $\geq 2$ vessel diameters;

- Grade 5 (G5), total occlusion, unable to assess thrombus burden due to total vessel occlusion.

Inclusion criteria were: age $\geq 65$ years with a confirmed frail condition (see below); presentation to the hospital for PPCI in the setting of first STEMI and feasibility of performing TA, as judged by the cardiologists. Patients with age $<65$ years or non-frails, left ventricular ejection fraction $<25 \%$, with previous myocardial infarction, revascularization, fibrinolytic therapy, or terminal cancer were excluded from the study. The investigation was designed and conducted according to the principles outlined in the Declaration of Helsinki for use of human tissue or subjects. The Institutional Review Board of University of Campania "Luigi Vanvitelli", Naples, Italy approved the protocol and written informed consent was given by each patient.

Physical frailty assessment was performed right before the discharge, following the Fried Criteria [3, 35]. A diagnosis of frailty status was made in presence of at least three points out of five:

- Weight loss (unintentional loss of $\geq 4.5 \mathrm{~kg}$ in the past year).

- Weakness (handgrip strength in the lowest 20\% quintile at baseline, adjusted for sex and body mass index).

- Exhaustion (poor endurance and energy, self-reported).

- Slowness (walking speed under the lowest quintile adjusted for sex and height).

- Low physical activity level (lowest quintile of kilocalories of physical activity during the past week).

Routine blood analyses were obtained on admission before coronary angiography. TA procedure was performed as previously described [14]. All patients (PPCI and TA + PPCI) were treated with adenosine (given $120 \mu \mathrm{g}$ as a fast bolus followed by $2 \mathrm{mg}$ in $2 \mathrm{~min}$ ) and with bolus infusion of abciximab ( $0.25 \mathrm{mg} / \mathrm{kg}$ i.v. bolus); 30 days after the procedure, all patients returned to our ambulatory for follow-up. The primary outcome was all-cause and cardiovascular death. Other outcomes were re-hospitalization for ACS and HF.

\section{Statistical analysis}

Clinical characteristics of patients were compared using the Pearson Chi square test for categorical variables and Student's $t$ test for continuous variables. Normality was assessed using the Shapiro-Wilk test. We calculated Kaplan-Meier product limits for cumulative probability of reaching an endpoint and used the log-rank test for evidence of a statistically significant difference between the groups; time was measured from the first admission for the procedure until outcome. We calculated via a priori power analysis (GPOWER software) the number of patients required to reject the null hypothesis with a one-tailed type II error rate of 0.05 and a two-tailed type I error of 0.05 , yielding a value of 184 participants. All calculations have been performed using the software SPSS 24. 


\section{Results}

A total of 956 frail patients with suspected STEMI were admitted to the PCI center. 298 patients were excluded because PPCI was not performed, 182 patients were excluded for delays in treatment greater than $24 \mathrm{~h}, 61$ patients were unwilling to provide clinical information, and biochemical analysis was not available for 26 subjects. Hence, a total of 389 patients completed the study (Fig. 1). There were no differences in the mean age, BMI, sex distribution, smoking habits, plasma cholesterol, and triglyceride levels between the two groups (Table 1).

The use of diuretics, angiotensin-converting enzyme inhibitors, beta-blockers, and calcium blockers was similar between the two groups (Table 1). Comorbidities are reported in Table 1. Angiographic data are summarized in Table 1 as well, showing that the treated lesion and the stent types were similar in the groups.

Lesion location, classification, angiographic measurements, and frequency of multi-lesion PPCI were also not significantly different between the two groups. TIMI-flow grade, corrected TIMI frame count, and myocardial blush grade pre-PPCI were similar between the two groups, whereas they were significantly improved in TA patients following PPCI; however, there was no significant difference in TIMI-flow 1 and myocardial blush grade 1 between the two groups (Table 1).

Clinical outcomes At 30-day follow-up, the mortality from any cause was $7.0 \%$ in patients treated with PPCI alone $v s 3.0 \%$ in patients treated with TA + PPCI $(p 0.036)$ (Fig. 2). Similarly, death from cardiovascular causes was $6.0 \%$ in the PPCI group $v s 3.0 \%$ in the TA + PPCI group ( $p$ 0.028) (Fig. 2).

Fig. 1 Study flow diagram

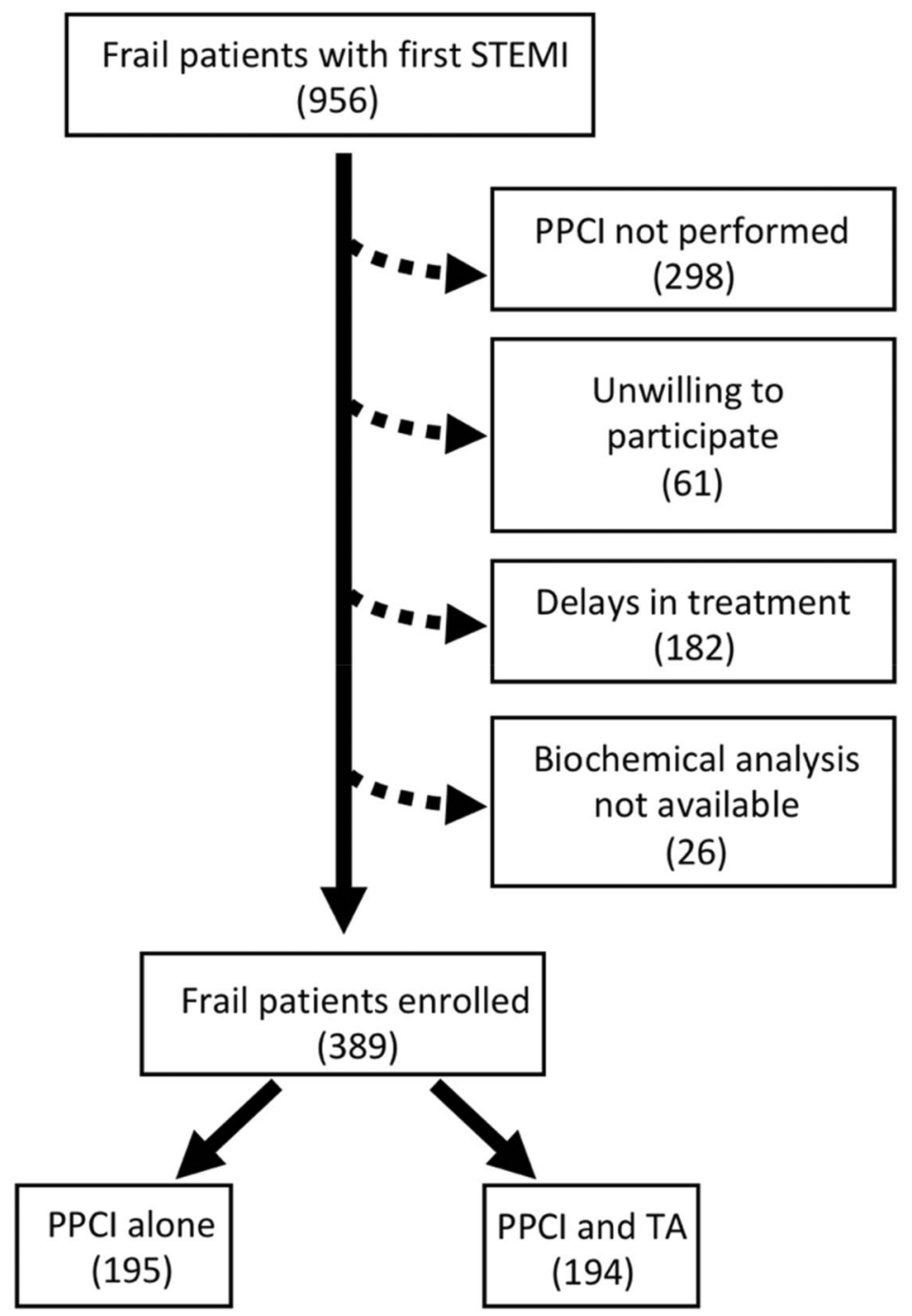


Table 1 Baseline and follow-up clinical characteristics, angiographic and procedural data

\begin{tabular}{|c|c|c|c|c|}
\hline & \multicolumn{2}{|l|}{ PPCI } & \multicolumn{2}{|l|}{$\mathrm{TA}+\mathrm{PPCI}$} \\
\hline & Baseline & Follow-up & Baseline & Follow-up \\
\hline & $n 195$ & $n 181$ & $n 194$ & $n 188$ \\
\hline Age (years) & $72 \pm 5.5$ & l & $71.5 \pm 5.0$ & l \\
\hline Female sex, $n(\%)$ & 104 & I & 102 & l \\
\hline BMI $\left(\mathrm{kg} / \mathrm{m}^{2}\right)$ & $28.1 \pm 1.7$ & $27.2 \pm 1.8$ & $28.3 \pm 1.6$ & $26.6 \pm 1.8$ \\
\hline $\mathrm{SBP}(\mathrm{mmHg})$ & $131.2 \pm 10.5$ & $127.2 \pm 9.0^{*}$ & $131.4 \pm 9.0$ & $125.3 \pm 8.5^{*}$ \\
\hline DBP $(\mathrm{mmHg})$ & $78.6 \pm 6.6$ & $76.3 \pm 6.5$ & $79.2 \pm 6.8$ & $76.3 \pm 6.8$ \\
\hline Heart rate (bpm) & $87.1 \pm 7.9$ & $76.1 \pm 6.9^{*}$ & $87.0 \pm 9.4$ & $75.2 \pm 9.3^{*}$ \\
\hline Cigarette smoking, n (\%) & $81(41.5)$ & & $79(41.0)$ & \\
\hline \multicolumn{5}{|l|}{ TIMI flow grade pre } \\
\hline Grade $0, n(\%)$ & $86(44.0)$ & & $87(46.0)$ & \\
\hline Grade $1, n(\%)$ & $16(8.0)$ & & $13(7.0)$ & \\
\hline Grade $2 / 3, n(\%)$ & $93(48.0)$ & & $92(47.0)$ & \\
\hline \multicolumn{5}{|l|}{ TIMI flow grade post } \\
\hline Grade $0, n(\%)$ & $11(5.5)$ & & $3(1.5)^{* *}$ & \\
\hline Grade $1, n(\%)$ & $58(30.0)$ & & $49(25.5)$ & \\
\hline Grade $2 / 3, n(\%)$ & $126(64.5)$ & & $142(73.0)^{* *}$ & \\
\hline \multicolumn{5}{|l|}{ Myocardial blush grade pre } \\
\hline Grade $0, n(\%)$ & $82(42.0)$ & & $89(46.0)$ & \\
\hline Grade $1, n(\%)$ & $14(7.0)$ & & $10(5.0)$ & \\
\hline Grade $2 / 3, n(\%)$ & $99(51.0)$ & & $95(49.0)$ & \\
\hline \multicolumn{5}{|l|}{ Myocardial blush grade post } \\
\hline Grade $0, n(\%)$ & $16(8.0)$ & & $5(3.0)^{* *}$ & \\
\hline Grade $1, n(\%)$ & $59(30.5)$ & & $44(22.5)$ & \\
\hline Grade $2 / 3, n(\%)$ & $120(61.5)$ & & $145(74.5)^{* *}$ & \\
\hline Corrected TIMI frame count pre & $83.4 \pm 24.1$ & & $87.8 \pm 23.3$ & \\
\hline Corrected TIMI frame count post & $31.1 \pm 23.8$ & & $24.7 \pm 19.2 * *$ & \\
\hline \multicolumn{5}{|l|}{ Killip class } \\
\hline Class $1, n(\%)$ & $59(30.5)$ & & $56(29)$ & \\
\hline Class $2, n(\%)$ & $51(26)$ & & $62(32)$ & \\
\hline Class $3, n(\%)$ & $82(42.0)$ & & $72(37)$ & \\
\hline Class $4, n(\%)$ & $3(1.5)$ & & $4(2)$ & \\
\hline \multicolumn{5}{|l|}{ Thrombus grade } \\
\hline G0 none & $16(8.0)$ & & $18(9.0)$ & \\
\hline G1 possible & $27(14.0)$ & & $25(13.0)$ & \\
\hline G2 small & $20(10.0)$ & & $23(12.0)$ & \\
\hline G3 medium & $33(17.0)$ & & $29(15.0)$ & \\
\hline G4 large & $37(19.0)$ & & $35(18.0)$ & \\
\hline G5 vessel occlusion & $62(32.0)$ & & $64(33.0)$ & \\
\hline \multicolumn{5}{|l|}{ Comorbidities } \\
\hline Diabetes, $n(\%)$ & $121(62.0)$ & & $122(61.0)$ & \\
\hline Hypertension, $n(\%)$ & $138(70.0)$ & & $134(68.0)$ & \\
\hline Dyslipidemia, $n(\%)$ & $90(46.0)$ & & $88(45.0)$ & \\
\hline Prior Stroke, $n(\%)$ & $16(8.5)$ & & $15(8.0)$ & \\
\hline Cerebrovascular disease, $n(\%)$ & $32(17.0)$ & & $30(16.5)$ & \\
\hline Chronic lung disease, $n(\%)$ & $26(14.0)$ & & $27(15)$ & \\
\hline \multicolumn{5}{|l|}{ Active treatments } \\
\hline$\beta$-Blockers, $n(\%)$ & $137(70)$ & $174(89.0)^{*}$ & $134(68.0)$ & $178(89.0)^{*}$ \\
\hline ACE inhibitors, $n(\%)$ & $104(53.0)$ & $106(54.0)$ & $105(54.0)$ & $114(57.0)$ \\
\hline Angiotensin receptor blockers, $n(\%)$ & $30(16.0)$ & $40(20.0)$ & $33(17.5)$ & $45(22.5)$ \\
\hline
\end{tabular}


Table 1 (continued)

\begin{tabular}{|c|c|c|c|c|}
\hline & \multicolumn{2}{|l|}{ PPCI } & \multicolumn{2}{|l|}{$\mathrm{TA}+\mathrm{PPCI}$} \\
\hline & Baseline & Follow-up & Baseline & Follow-up \\
\hline & $n 195$ & $n 181$ & $n 194$ & $n 188$ \\
\hline Calcium inhibitors, $n(\%)$ & $42(21.5)$ & $59(29.5)$ & $48(24.0)$ & $55(27.5)$ \\
\hline Nitrate, $n(\%)$ & / & $156(79.0)$ & l & $167(85.0)$ \\
\hline Statins, $n(\%)$ & $54(27.5)$ & $195(98.5)^{*}$ & $55(27.5)$ & $191(99.0)^{*}$ \\
\hline Diuretic, $n(\%)$ & $16(8.5)$ & $49(24.5)^{*}$ & $16(8.0)$ & $43(21.5)^{*}$ \\
\hline Insulin, $n(\%)$ & $34(17.5)$ & $45(22.5)$ & $35(17.5)$ & $47(23.0)$ \\
\hline Oral antidiabetic, $n(\%)$ & $48(24.5)$ & $80(40.0)^{*}$ & $45(23.0)$ & $89(44.5)^{*}$ \\
\hline Aspirin, $n(\%)$ & $49(25.0)$ & $192(99.0)^{*}$ & $44(22.5)$ & $191(99.0)$ \\
\hline \multicolumn{5}{|l|}{ Thienopyridine, $n(\%)$} \\
\hline Dual anti-platelet therapy, $n(\%)$ & / & $183(91.5)$ & / & $193(96.5)^{* * *}$ \\
\hline Low-molecular weight heparin, $n(\%)$ & / & $14(7.0)$ & I & $28(14.0)^{* * *}$ \\
\hline Vitamin-K antagonist, $n(\%)$ & l & $12(6.0)$ & l & $11(5.5)$ \\
\hline \multicolumn{5}{|l|}{ Laboratory parameters } \\
\hline Plasma glucose (mg/dl) & $191.1 \pm 22.7$ & $126.4 \pm 23.3^{*}$ & $190.3 \pm 20.2$ & $121.2 \pm 21.3 *, * * *$ \\
\hline Cholesterol (mg/dl) & $205.2 \pm 20.4$ & $202.2 \pm 20.4$ & $204.6 \pm 22.6$ & $192.8 \pm 24.7 * * *$ \\
\hline LDL-cholesterol (mg/dl) & $132.7 .9 \pm 17.6$ & $128.2 \pm 20.1$ & $131.1 \pm 21.5$ & $122.8 \pm 25.1 * * * *$ \\
\hline HDL-cholesterol (mg/dl) & $38.2 \pm 6.4$ & $42.2 \pm 3.4$ & $37.1 \pm 3.5$ & $38.9 \pm 3.5^{* * *}$ \\
\hline Triglycerides (mg/dl) & $181.0 \pm 19.1$ & $159.0 \pm 19.1 *$ & $185.0 \pm 24.0 * *$ & $145.6 \pm 31.1 *, * * *$ \\
\hline Creatinine (mg/dl) & $1.0 \pm 0.1$ & $1.0 \pm 0.1$ & $1.0 \pm 0.1$ & $1.0 \pm 0.1$ \\
\hline cTnT (ng/l) & $5.4 \pm 1.5$ & I & $5.6 \pm 1.4$ & I \\
\hline \multicolumn{5}{|l|}{ Angiography data } \\
\hline \multicolumn{5}{|l|}{ Number of diseased vessels } \\
\hline $1-\mathrm{VD}, n(\%)$ & $150(75.5)$ & I & $153(78.0)$ & / \\
\hline 2-VD, $n(\%)$ & $43(23.5)$ & l & $40(21.5)$ & l \\
\hline 3-VD, $n(\%)$ & $2(1.0)$ & l & $1(0.5)$ & I \\
\hline \multicolumn{5}{|l|}{ Lesion location } \\
\hline $\mathrm{RCA}, n(\%)$ & $61(31.5)$ & l & $68(35.0)$ & l \\
\hline $\mathrm{LAD}, n(\%)$ & $86(44.0)$ & l & $83(42.5)$ & l \\
\hline $\mathrm{LM}, n(\%)$ & $7(3.5)$ & l & $8(4.0)$ & l \\
\hline $\mathrm{LCx}, n(\%)$ & $41(21.0)$ & l & $35(18.5)$ & l \\
\hline \multicolumn{5}{|l|}{ LVEF } \\
\hline$>50 \%, n(\%)$ & $108(55.0)$ & $129(65.5)$ & $112(57.0)$ & $142(72.5)^{*}$ \\
\hline $41-50 \%, n(\%)$ & $59(35.5)$ & $59(31.0)$ & $52(27.5)^{* *}$ & $49(26.0)$ \\
\hline $25-40 \%, n(\%)$ & $28(14.5)$ & $7(3.5)^{*}$ & $30(15.5)$ & $3(1.5)^{*}$ \\
\hline \multicolumn{5}{|l|}{ Stent type } \\
\hline DES, $n(\%)$ & $170(86.0)$ & I & $176(90.0)$ & I \\
\hline $\mathrm{BMS}, n(\%)$ & $25(14.0)$ & l & $18(10.0)$ & l \\
\hline Multivessel intervention, $n(\%)$ & $49(24.5)$ & / & $44(22.0)$ & l \\
\hline
\end{tabular}

Data are mean $\pm \mathrm{SD}$ or $n(\%)$

1-VD single-vessel disease, 2-VD two-vessel disease, 3-VD three-vessel disease, BMS bare metal stent, $D B P$ diastolic blood pressure, $D E S$ drug-eluting stent, $L A D$ left anterior descending, $L C x$ left circumflex artery, $L M$ left main, $L V E F$ left ventricular ejection fraction, $M L D$ minimum luminal diameter, $P P C I$ primary percutaneous coronary intervention, $R C A$ right coronary artery, $S B P$ systolic blood pressure, $T A$ thrombus aspiration

The symbol $*$ is indicating a $p<0.05$ with the comparison of baseline vs. follow-up; the symbol $* *$ is indicating the $p<0.05$ with the comparison of baseline PPCI vs. Baseline TA + PPCI; the symbol $* * *$ is indicating the $p<0.05$ with the comparison of follow-up PPCI vs. TA + PPCI 

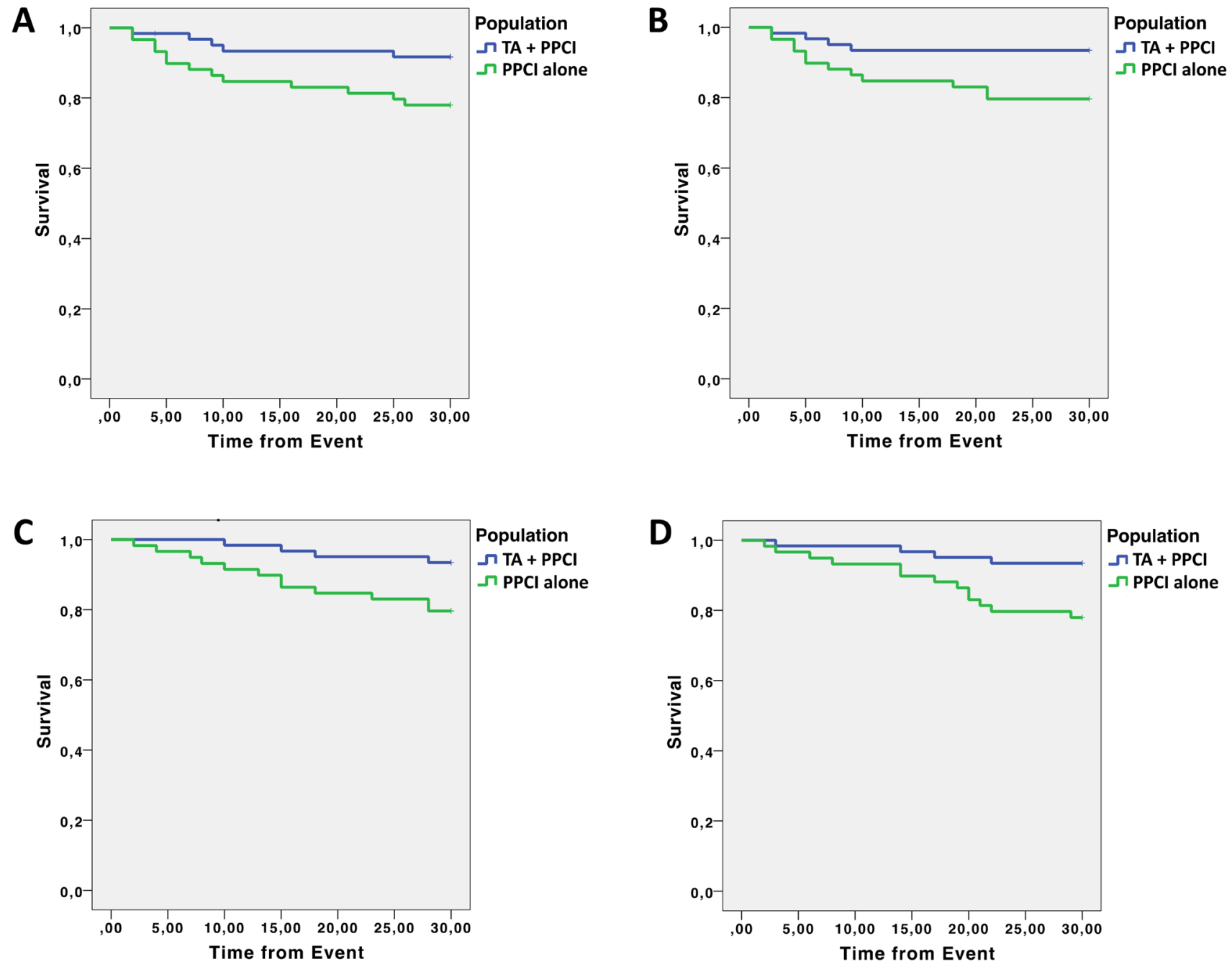

Fig. 2 Kaplan-Meier curves for clinical outcomes: a death, $\mathbf{b}$ cardiac death, $\mathbf{c}$ re-hospitalization for HF, $\mathbf{d}$ re-hospitalization for ACS

The rate of re-hospitalization due to $\mathrm{HF}$ was $7.5 \%$ in the PPCI group vs $4.0 \%$ in TA + PPCI group ( $p$ 0.025) (Fig. 2). The rate of re-hospitalization due to ACS was $10.0 \%$ in the PPCI group vs $4.5 \%$ in the TA + PPCI ( $p$ 0.016) (Fig. 2). These results were confirmed by a multivariate analysis adjusted for age, hypertension, diabetes, and COPD.

\section{Discussion}

The exact role of coronary TA in PPCI for STEMI is very debated [21, 23, 36-40]. Indeed, whereas early trial results encouraged this procedure, large randomized trials did not show significant clinical benefits in the general population [41, 42]. However, a recent study comparing TA + PPCI to PPCI alone evidenced lower mortality and better survival in hyperglycemic patients [14]. These results underscore the importance of TA in a group of high-risk patients such as subjects with hyperglycemia in preserving microvascular perfusion and reducing the subsequent occurrence of distal embolization and microvascular obstruction [14]. Interestingly, the presence of hyperglycemia could increase the production of oxidative stress and inflammation, responsible for the dysfunction of the microcirculation, leading to the formation of thrombi and/or atherosclerotic plaques [12].

Frail patients are known to present an intrinsic risk of cardiovascular diseases with higher mortality and higher risk of re-hospitalization $[5,7,43]$. Furthermore, they present a high oxidative stress and the oxidative damage inasmuch as the aging process itself impairs physiological functions and increases the incidence of cardiovascular diseases [13, 44-48]. Interestingly, myocardial blush grade, a parameter commonly used to assess microvascular flow [30], was better in the TA group. This finding may underline the importance of TA in protecting from distal embolization and microvascular obstruction in frailty. 
The most impactful result of our study, shown by Kaplan-Meier curves, was on the hospitalization rate for ACS at 30-day follow-up (Fig. 2). Significant results were also obtained on death, cardiovascular death, as well as rehospitalization for HF (at 30 days follow-up) (Fig. 1). Potential mechanisms underlying these observations include a reduced distal embolization and an improved microvascular perfusion; indeed, patients in the TA + PPCI group exhibited a better TIMI Flow grade compared to PPCI patients. This finding is especially striking because TA may represent a key determinant to prevent no-reflow phenomena in frail subjects and may open new fields of investigation in the management of STEMI in frail patients.

Nowadays, TA + PPCI is debated; some years ago, it was considered an important aspect of PPCI, particularly in patients with a high thrombus burden [15, 49-51]. Considering their comorbidities, frail patients could represent a sub-class in which TA + PPCI may have a great impact.

Several limitations of the present study warrant consideration. First, the follow-up period of 30 days is short; nevertheless, observing significant differences between PPCI and TA + PPCI in several outcomes already after 1 month is noteworthy, especially in a population of elderly patients. Second, the sample size of our two groups is relatively small; however, as mentioned in "Methods", we had performed an a priori power analysis, based on our preliminary data, showing that the estimated sample size was 184 patients. We did not evaluate the neurological and cerebrovascular outcomes in our population, which remain a controversial point of TA: indeed, whereas an increased risk of stroke has been reported in the Trial of Routine Aspiration Thrombectomy with PCI versus PCI Alone in Patients with STEMI (TOTAL) [19], such a finding has not been confirmed in the Thrombus Aspiration in ST-Elevation Myocardial Infarction in Scandinavia (TASTE) [21] or in the SCAAR [23] studies. Further studies, ideally randomized trials focused on elderly populations, with longer follow-up and larger cohorts, are required to confirm our results.

\section{Conclusions}

Taken together, our data suggest that in the treatment of STEMI, adding TA to PPCI is associated with a significant improvement in 30-day mortality and hospitalizations due to HF and ACS in frail elderly patients, compared to conventional PPCI alone.

Funding Open access funding provided by Università degli Studi di Napoli Federico II within the CRUI-CARE Agreement. The Santulli Lab is supported in part by the National Institutes of Health (NIH: R01-DK123259, R01-HL146691, R01-DK033823, R01-HL159062, R56-AG066431, T32-HL144456, R00-DK107895, to G.S.), by the
Irma T. Hirschl and Monique Weill-Caulier Trusts (to G.S.), and by the AHA (20POST-35211151) to J.G.

Data availability statement All data and materials are presented in the main paper.

\section{Declarations}

Conflict of interest The authors declare that they have no conflict of interest.

Statement of human and animal rights All procedures performed in the study were in accordance with the ethical standards of the Vanvitelli University Ethics Committee and with the 1964 Helsinki declaration and its later amendments.

Informed consent Written informed consent was given by each patient. All data were anonymized.

Open Access This article is licensed under a Creative Commons Attribution 4.0 International License, which permits use, sharing, adaptation, distribution and reproduction in any medium or format, as long as you give appropriate credit to the original author(s) and the source, provide a link to the Creative Commons licence, and indicate if changes were made. The images or other third party material in this article are included in the article's Creative Commons licence, unless indicated otherwise in a credit line to the material. If material is not included in the article's Creative Commons licence and your intended use is not permitted by statutory regulation or exceeds the permitted use, you will need to obtain permission directly from the copyright holder. To view a copy of this licence, visit http://creativecommons.org/licenses/by/4.0/.

\section{References}

1. Ungar A, Rivasi G, Petrovic M et al (2020) Toward a geriatric approach to patients with advanced age and cardiovascular diseases: position statement of the EuGMS special interest group on cardiovascular medicine. Eur Geriatr Med 11:179-184. https:// doi.org/10.1007/s41999-019-00267-0

2. Dodson JA, Geda M, Krumholz HM et al (2014) Design and rationale of the comprehensive evaluation of risk factors in older patients with AMI (SILVER-AMI) study. BMC Health Serv Res 14:506. https://doi.org/10.1186/s12913-014-0506-4

3. Afilalo J, Alexander KP, Mack MJ et al (2014) Frailty assessment in the cardiovascular care of older adults. J Am Coll Cardiol 63:747-762. https://doi.org/10.1016/j.jacc.2013.09.070

4. Forman DE, Arena R, Boxer R et al (2017) Prioritizing functional capacity as a principal end point for therapies oriented to older adults with cardiovascular disease: a scientific statement for healthcare professionals from the American Heart Association. Circulation 135:e894-e918. https://doi.org/10.1161/CIR.00000 00000000483

5. Singh M, Rihal CS, Lennon RJ et al (2011) Influence of frailty and health status on outcomes in patients with coronary disease undergoing percutaneous revascularization. Circ Cardiovasc Qual Outcomes 4:496-502. https://doi.org/10.1161/CIRCOUTCOMES. 111.961375

6. Goldfarb M, Afilalo J, Chan A et al (2018) Early mobility in frail and non-frail older adults admitted to the cardiovascular intensive care unit. J Crit Care 47:9-14. https://doi.org/10.1016/j.jcrc.2018. 05.013 
7. Patel A, Goodman SG, Yan AT et al (2018) Frailty and outcomes after myocardial infarction: insights from the CONCORDANCE Registry. J Am Heart Assoc 7:e009859. https://doi.org/10.1161/ JAHA.118.009859

8. Malkin CJ, Prakash R, Chew DP (2012) The impact of increased age on outcome from a strategy of early invasive management and revascularisation in patients with acute coronary syndromes: retrospective analysis study from the ACACIA registry. BMJ Open 2:e000540. https://doi.org/10.1136/bmjopen-2011-000540

9. Toleva O, Ibrahim Q, Brass N et al (2015) Treatment choices in elderly patients with ST: elevation myocardial infarction-insights from the Vital Heart Response registry. Open Heart 2:e000235. https://doi.org/10.1136/openhrt-2014-000235

10. Ibanez B, Heusch G, Ovize M et al (2015) Evolving therapies for myocardial ischemia/reperfusion injury. J Am Coll Cardiol 65:1454-1471. https://doi.org/10.1016/j.jacc.2015.02.032

11. Ikari Y, Sakurada M, Kozuma K et al (2008) Upfront thrombus aspiration in primary coronary intervention for patients with ST-segment elevation acute myocardial infarction: report of the VAMPIRE (VAcuuM asPIration thrombus REmoval) trial. JACC Cardiovasc Interv 1:424-431. https://doi.org/10.1016/j.jcin.2008. 06.004

12. Niccoli G, Scalone G, Lerman A et al (2016) Coronary microvascular obstruction in acute myocardial infarction. Eur Heart $\mathrm{J}$ 37:1024-1033. https://doi.org/10.1093/eurheartj/ehv484

13. Soysal P, Isik AT, Carvalho AF et al (2017) Oxidative stress and frailty: a systematic review and synthesis of the best evidence. Maturitas 99:66-72. https://doi.org/10.1016/j.maturitas.2017.01. 006

14. Sardu C, Barbieri M, Balestrieri ML et al (2018) Thrombus aspiration in hyperglycemic ST-elevation myocardial infarction (STEMI) patients: clinical outcomes at 1-year follow-up. Cardiovasc Diabetol 17:152. https://doi.org/10.1186/s12933-018-0795-8

15. Mangiacapra F, Sticchi A, Barbato E (2017) Thrombus aspiration in primary percutaneous coronary intervention: still a valid option with improved technique in selected patients! Cardiovasc Diagn Ther 7:S110-S114. https://doi.org/10.21037/cdt.2017.05.09

16. Burzotta F, De Vita M, Gu YL et al (2009) Clinical impact of thrombectomy in acute ST-elevation myocardial infarction: an individual patient-data pooled analysis of 11 trials. Eur Heart $\mathrm{J}$ 30:2193-2203. https://doi.org/10.1093/eurheartj/ehp348

17. Mahmoud KD, Zijlstra F (2016) Thrombus aspiration in acute myocardial infarction. Nat Rev Cardiol 13:418-428. https://doi. org/10.1038/nrcardio.2016.38

18. Yunoki K, Naruko T, Sugioka K et al (2013) Thrombus aspiration therapy and coronary thrombus components in patients with acute ST-elevation myocardial infarction. J Atheroscler Thromb 20:524-537. https://doi.org/10.5551/jat.17608

19. Jolly SS, Cairns JA, Yusuf S et al (2016) Outcomes after thrombus aspiration for ST elevation myocardial infarction: 1-year follow-up of the prospective randomised TOTAL trial. Lancet 387:127-135. https://doi.org/10.1016/S0140-6736(15)00448-1

20. Lagerqvist B, Frobert O, Olivecrona GK et al (2014) Outcomes 1 year after thrombus aspiration for myocardial infarction. N Engl J Med 371:1111-1120. https://doi.org/10.1056/NEJMoa1405707

21. Frobert O, Lagerqvist B, Olivecrona GK et al (2013) Thrombus aspiration during ST-segment elevation myocardial infarction. $\mathrm{N}$ Engl J Med 369:1587-1597. https://doi.org/10.1056/NEJMoa1308 789

22. Tilsted HH, Olivecrona GK (2015) To aspirate or not to aspirate: that is the question. JACC Cardiovasc Interv 8:585-587. https:// doi.org/10.1016/j.jcin.2015.01.014

23. Angeras O, Haraldsson I, Redfors B et al (2018) Impact of thrombus aspiration on mortality, stent thrombosis, and stroke in patients with ST-segment-elevation myocardial infarction: a report from the Swedish Coronary Angiography and Angioplasty
Registry. J Am Heart Assoc. https://doi.org/10.1161/JAHA.117. 007680

24. Fokkema ML, James SK, Albertsson P et al (2013) Population trends in percutaneous coronary intervention: 20-year results from the SCAAR (Swedish Coronary Angiography and Angioplasty Registry). J Am Coll Cardiol 61:1222-1230. https://doi.org/10. 1016/j.jacc.2013.01.007

25. Group EUCCS, Regitz-Zagrosek V, Oertelt-Prigione S et al (2016) Gender in cardiovascular diseases: impact on clinical manifestations, management, and outcomes. Eur Heart J 37:24-34. https:// doi.org/10.1093/eurheartj/ehv598

26. Achilli F, Malafronte C, Cesana F et al (2015) Granulocyte-colony stimulating factor for large anterior ST-elevation myocardial infarction: rationale and design of the prospective randomized phase III STEM-AMI OUTCOME trial. Am Heart J 170:652-658. https://doi.org/10.1016/j.ahj.2015.07.005

27. Montalescot G, Bolognese L, Dudek D et al (2013) Pretreatment with prasugrel in non-ST-segment elevation acute coronary syndromes. N Engl J Med 369:999-1010. https://doi.org/10.1056/ NEJMoa1308075

28. Marfella R, Sasso FC, Siniscalchi M et al (2012) Peri-procedural tight glycemic control during early percutaneous coronary intervention is associated with a lower rate of in-stent restenosis in patients with acute ST-elevation myocardial infarction. $\mathrm{J}$ Clin Endocrinol Metab 97:2862-2871. https://doi.org/10.1210/ jc. $2012-1364$

29. Gibson CM, Cannon CP, Murphy SA et al (2000) Relationship of TIMI myocardial perfusion grade to mortality after administration of thrombolytic drugs. Circulation 101:125-130. https:// doi.org/10.1161/01.cir.101.2.125

30. Henriques JP, Zijlstra F, van't Hof AW et al (2003) Angiographic assessment of reperfusion in acute myocardial infarction by myocardial blush grade. Circulation 107:2115-2119. https://doi.org/10.1161/01.CIR.0000065221.06430.ED

31. Porto I, Hamilton-Craig C, Brancati M et al (2010) Angiographic assessment of microvascular perfusion-myocardial blush in clinical practice. Am Heart J 160:1015-1022. https:// doi.org/10.1016/j.ahj.2010.08.009

32. Sharma V, Jolly SS, Hamid T et al (2016) Myocardial blush and microvascular reperfusion following manual thrombectomy during percutaneous coronary intervention for ST elevation myocardial infarction: insights from the TOTAL trial. Eur Heart J 37:1891-1898. https://doi.org/10.1093/eurheartj/ehw157

33. Sianos G, Papafaklis MI, Serruys PW (2010) Angiographic thrombus burden classification in patients with ST-segment elevation myocardial infarction treated with percutaneous coronary intervention. J Invasive Cardiol 22:6B-14B

34. Sianos G, Papafaklis MI, Daemen J et al (2007) Angiographic stent thrombosis after routine use of drug-eluting stents in STsegment elevation myocardial infarction: the importance of thrombus burden. J Am Coll Cardiol 50:573-583. https://doi. org/10.1016/j.jacc.2007.04.059

35. Hoogendijk EO, Afilalo J, Ensrud KE et al (2019) Frailty: implications for clinical practice and public health. Lancet 394:13651375. https://doi.org/10.1016/S0140-6736(19)31786-6

36. Garcia-Blas S, Sanchis J (2020) The long road for tailored STEMI strategies but a short path for thrombus aspiration. Int J Cardiol. https://doi.org/10.1016/j.ijcard.2020.06.047

37. Kumar D, Patra S, Pande A et al (2020) Long-term clinical outcomes of thrombus aspiration in STEMI patients undergoing primary percutaneous coronary intervention. Am J Cardiovasc Dis 10:117-123

38. Qin X, Luo J, Qin L et al (2020) Long-term impact of thrombus aspiration in patients with ST-elevation myocardial infarction undergoing primary percutaneous coronary intervention. Am 
J Cardiol 125:1471-1478. https://doi.org/10.1016/j.amjcard. 2020.02.025

39. Binder RK (2019) Look beyond what seems obvious: thrombus burden after aspiration thrombectomy. Eur Heart J 40:e14-e16. https://doi.org/10.1093/eurheartj/ehv231

40. Desch S, Stiermaier T, Thiele $\mathrm{H}$ et al (2017) Requiem for routine thrombus aspiration. Cardiovasc Diagn Ther 7:S107-S109. https://doi.org/10.21037/cdt.2017.05.02

41. Jolly SS, James S, Dzavik V et al (2017) Thrombus aspiration in ST-segment-elevation myocardial infarction: an individual patient meta-analysis: thrombectomy trialists collaboration. Circulation 135:143-152. https://doi.org/10.1161/CIRCULATIO NAHA.116.025371

42. Vaduganathan M, Bhatt DL (2015) Manual thrombectomy in myocardial infarction: aspiring for better. J Am Heart Assoc 4:002201. https://doi.org/10.1161/JAHA.115.002201

43. Veronese N, Cereda E, Stubbs B et al (2017) Risk of cardiovascular disease morbidity and mortality in frail and pre-frail older adults: results from a meta-analysis and exploratory meta-regression analysis. Ageing Res Rev 35:63-73. https://doi.org/10.1016/j. arr.2017.01.003

44. Taglieri N, Reggiani MLB, Ghetti G et al (2019) Efficacy and safety of thrombus aspiration in ST-segment elevation myocardial infarction: an updated systematic review and meta-analysis of randomised clinical trials. Eur Heart J Acute Cardiovasc Care 8:24-38. https://doi.org/10.1177/2048872618795512

45. Ingles M, Gambini J, Carnicero JA et al (2014) Oxidative stress is related to frailty, not to age or sex, in a geriatric population: lipid and protein oxidation as biomarkers of frailty. J Am Geriatr Soc 62:1324-1328. https://doi.org/10.1111/jgs.12876
46. Mulero J, Zafrilla P, Martinez-Cacha A (2011) Oxidative stress, frailty and cognitive decline. J Nutr Health Aging 15:756-760. https://doi.org/10.1007/s12603-011-0130-5

47. Serviddio G, Romano AD, Greco A et al (2009) Frailty syndrome is associated with altered circulating redox balance and increased markers of oxidative stress. Int J Immunopathol Pharmacol 22:819-827. https://doi.org/10.1177/039463200902200328

48. Fuentes F, Palomo I, Fuentes E (2017) Platelet oxidative stress as a novel target of cardiovascular risk in frail older people. Vascul Pharmacol 93-95:14-19. https://doi.org/10.1016/j.vph.2017.07. 003

49. Moscarella E, Brugaletta S, Sabate M (2018) Latest STEMI treatment: a focus on current and upcoming devices. Expert Rev Med Devices 15:807-817. https://doi.org/10.1080/17434440.2018. 1538778

50. Ge J, Schafer A, Ertl G et al (2017) Thrombus aspiration for STsegment-elevation myocardial infarction in modern era: still an issue of debate? Circ Cardiovasc Interv. https://doi.org/10.1161/ CIRCINTERVENTIONS.117.005739

51. El Dib R, Spencer FA, Suzumura EA et al (2016) Aspiration thrombectomy prior to percutaneous coronary intervention in ST-elevation myocardial infarction: a systematic review and metaanalysis. BMC Cardiovasc Disord 16:121. https://doi.org/10.1186/ s12872-016-0285-4

Publisher's Note Springer Nature remains neutral with regard to jurisdictional claims in published maps and institutional affiliations. 